\title{
GP access to FIT increases the proportion of Colorectal Cancers detected on urgent pathways in symptomatic patients in Nottingham.
}

Bailey $\mathrm{JA}^{1}$, Khawaja $\mathrm{A}^{1}$, Andrews $\mathrm{H}^{1}$, Weller $\mathrm{J}^{1}$, Chapman $\mathrm{C}^{2}$, Morling $\mathrm{J}^{2,4,5}$, Oliver $\mathrm{S}^{3}$, Castle $\mathrm{S}^{3}$, Simpson $\mathrm{JA}^{2}$, Humes $\mathrm{DJ}^{1,4,5}$ and Banerjea $\mathrm{A}^{1}$

Affiliations

${ }^{1}$ Nottingham Colorectal Service, E Floor West Block, QMC Campus, Nottingham University Hospitals NHS Trust, Nottingham, UK, NG7 2UH

${ }^{2}$ Eastern Hub, Bowel Cancer Screening Programme, A Floor West Block, QMC Campus, Nottingham University Hospitals NHS Trust, Nottingham, UK, NG7 2UH

${ }^{3}$ Nottingham City Clinical Commissioning Group

${ }^{4}$ NIHR Nottingham Biomedical Research Centre (BRC), Nottingham University Hospitals NHS Trust and the University of Nottingham, Nottingham, UK, NG7 2UH

${ }^{5}$ Division of Epidemiology and Public Health, School of Medicine, University of Nottingham, Clinical Sciences Building 2, City Hospital, Nottingham, UK, NG5 1PB

*Correspondence: Mr James Bailey: james.bailey4@ nhs.net

Funding: This research did not receive any specific grant from funding agencies in the public, commercial, or not-for-profit sectors. Pathway funded by local Clinical Commissioning Groups (Nottingham City, Nottingham North and East, Nottingham West and Rushcliffe) Original Article

Key Words: Colorectal cancer; Faecal Immunochemical Test; FIT; Symptomatic FIT; NG12 Short Title: Service Evaluation of FIT for Symptomatic CRC Detection 
Acknowledgements

Primary Care: Drs Elaine Maddock, Heetan Patel, Mike O’Neil, Matt Jelpke and Safiy Karim and all our Primary Care colleagues who accepted a significant change in working practice. Simon Castle and all colleagues in local CCG's who facilitated this service development.

Nottingham Colorectal Service: Sarah Thomson, Bev Harwood, Sarah Hall, Tara Dorn, Lillian Hamonga, Helen Andrews, Donna Bradshaw, Julian Williams, John Abercrombie, Charles Maxwell-Armstrong, Austin Acheson, Katie Walter, Bala Bharathan, Khalid Mohiuddin, Kathryn Thomas, Alastair Simpson, Arifa Siddika, Sarah Liptrot, Hammad Zaidi. Nottinghamshire Bowel Cancer Screening Hub: Katie Hardy, Abby Duffin and Richard Logan.

IT support: Karim Premji and Steven Murdock

Thanks to the Department of Gastroenterology Nottingham University Hospitals; Nottingham City Hospital Endoscopy Service and Department of Radiology, Nottingham University Hospitals. 


\begin{abstract}
Objective:

Service evaluation of GP access to Faecal Immunochemical Test (FIT) for colorectal cancer (CRC) detection in Nottinghamshire and use of FIT for "rule out", "rule in" and "first test selection".
\end{abstract}

Design:

Retrospective audit of FIT results, CRC outcomes and resource utilisation before and after introduction of FIT in Primary Care in November 2017. Data from the new pathway up to December 2018 was compared with previous experience.

Results:

Between November 2017 and December 2018, 6747 GP FIT test requests yielded 5733 FIT results, of which $4082(71.2 \%)$ were $<4.0 \mu \mathrm{g} \mathrm{Hb} / \mathrm{g}$ faeces, 579 (10.1\%) were 4.0-9.9 $\mu \mathrm{g} \mathrm{Hb} / \mathrm{g}$ faeces, $836(14.6 \%)$ were $10.0-149.9 \mu \mathrm{g} \mathrm{Hb} / \mathrm{g}$ faeces, and $236(4.1 \%)$ were $\geq 150.0 \mu \mathrm{g} \mathrm{Hb} / \mathrm{g}$ faeces. The proportion of "rule out" results $<4.0 \mu \mathrm{g} \mathrm{Hb} / \mathrm{g}$ faeces was significantly higher than in the Getting FIT cohort $(71.2 \%$ vs $60.4 \%$, Chi squared 42.8, $\mathrm{p}<0.0001)$ and the proportion of "rule in" results $\geq 150.0 \mu \mathrm{g} \mathrm{Hb} / \mathrm{g}$ faeces was significantly lower ( $4.1 \%$ vs $8.1 \%$, Chi squared 27.3,P<0.0001).

There was a 33\% rise in urgent referrals across Nottingham overall during the evaluation period. 2 CRC diagnoses were made in 4082 patients who had FIT $<4.0 \mu \mathrm{g} \mathrm{Hb} / \mathrm{g}$ faeces. $58.4 \%$ of new CRC diagnoses associated with a positive FIT were early stage cancers (Stage I and II). The proportion of all CRC diagnoses that follow an urgent referral s rose after introduction of FIT. 
Conclusions:

FIT allows GP's to select a more appropriate cohort for urgent investigation without a large number of missed diagnoses. FIT appears to promise a "stage migration" effect which may ultimately improve CRC outcomes. 


\section{Introduction}

Cancer outcomes in the United Kingdom lag behind the rest of Europe despite nearly two decades of concerted effort ${ }^{1}$. Colorectal cancer (CRC), a common cancer diagnosis and cause of cancer death ${ }^{2}$, remains an area of concern. This is not surprising as current criteria for urgent referral to secondary care are largely based on age and symptoms ${ }^{3}$ - the latter are often associated with later stage disease and inherently non-specific. The Bowel Cancer Screening Programme (BCSP) has demonstrated that CRC is often asymptomatic ${ }^{4}$. Many individuals with CRC have vague symptoms and younger patients with symptoms are sometimes inappropriately reassured by the doctrine that CRC is a disease of the elderly. Furthermore, in the NHS significant diagnostic capacity is engaged investigating and re-investigating individuals with no identifiable cause for their symptoms, in whom health and wellbeing input might actually be more clinically effective.

Segmentation and stratification of the Primary care population is key to improving early diagnosis for CRC. Simple measures such as a Full Blood Count (FBC) can identify markers such as anaemia ${ }^{5-7}$ and thrombocytosis ${ }^{8}$ that may have value. However, testing for occult blood in faeces - the basis of BCSP - currently holds much promise. Faecal Immunochemical Testing (FIT) is more sensitive and objective than Guaiac-based FOBT (gFOBT) and has been shown to be useful in patients with symptoms ${ }^{9-12}$. In 2015, NICE guidance opened the door to testing for occult blood in faeces in low risk patients, without clearly defining which test should be used ${ }^{3}$. In September 2016, we introduced a locally commissioned year-long pilot of FIT in our two week wait (2WW) population (excluding those with rectal bleeding) and demonstrated clear stratification value in all symptom groups $^{9}$. In November 2017, we introduced a Rapid Colorectal Cancer Diagnosis (RCCD) Pathway incorporating direct General Practitioner (GP) access to FIT and use of FIT results for "rule in", "rule out" and "first test" selection in secondary care ${ }^{13}$. We present an overview 
of the impact of GP access to FIT and RCCD on our local practice during the first year of this novel English pathway.

\section{Methods}

Rapid Colorectal Cancer Diagnosis Pathway (RCCD)

This "locally agreed" pathway was designed to incorporate FIT as a triage tool for all referral criteria, except rectal bleeding and rectal mass, as described elsewhere ${ }^{13}$. GPs were able to request FIT (and blood tests) independently and act on the result, or if clinical suspicion was high they could submit an RCCD referral form contemporaneously. In the latter pathway, the form was held for 12 working days in a "window" and the 62 day clock only started either on receipt of FIT (and blood) results or on expiry of the "window".

FIT requests and testing

FIT requests in Primary Care were made on an electronic request system (ICE) that also prompted requests for blood tests where indicated. Results were notified on the same electronic system with text guidance on how to interpret results and subsequent actions. An electronic guidance system F12 (SystemOne) was also used to guide GPs on the use of FIT and the new pathway in those practices that use this system, with direct links to the relevant referral form where appropriate.

FIT dispatch and return was entirely postal and kits were analysed according to manufacturer's protocols as described elsewhere'.

"Rule in" 
Patients with a FIT result $\geq 150 \mu \mathrm{g} \mathrm{Hb} / \mathrm{g}$ faeces were considered "high risk" positive and the result was notified directly by BCSP to the Nottingham Colorectal Service STT team as well as to the GP, irrespective of whether an RCCD form had been submitted. This cut-off threshold was selected for our previous pilot as an approximate equivalent to a positive gFOBT - the only alternative in clinical practice at the time $\left({ }^{9}\right)$. The STT team contacted these patients directly for vetting and appropriate investigation on a "rapid" pathway according to local protocols. Patients with a result $\geq 10 \mu \mathrm{g} \mathrm{Hb} / \mathrm{g}$ faeces of a result $\geq 4 \mu \mathrm{g} \mathrm{Hb} / \mathrm{g}$ faeces in the presence of anaemia were also considered positive and were investigated on a two week wait (2WW) pathway.

"Rule out"

Patients with a FIT result $<4 \mu \mathrm{g} \mathrm{Hb} / \mathrm{g}$ faeces were considered to have a "negative" FIT test and to be low risk for CRC. Patients with a FIT result $\geq 4$ but $<10 \mu \mathrm{g} \mathrm{Hb} / \mathrm{g}$ faeces were also considered "negative" if their Haemoglobin level was normal $(\geq 130 \mathrm{~g} / 1$ in men; $\geq 120 \mathrm{~g} / 1$ in women). GP's were advised that patients with negative FIT tests had low risk of CRC and management options were to consider an alternate urgent pathway, routine referral or repeat FIT testing.

"First test" selection

Patients with a "negative" FIT result in RCCD referrals for abdominal mass or weight loss were considered for Computerised Tomography (CT) with intravenous contrast. Patients with a "negative" FIT in RCCD referrals for Iron deficiency anaemia (IDA) were preferentially investigated with CT Colonography (CTC) rather than colonoscopy (with oesophagogastroduodenoscopy - OGD - if not undertaken recently). CTC was also chosen for patients who were frail, elderly or had other reasons to prefer non-invasive investigation as the first test (including patient choice). 
Patients referred with a rectal mass were not subject to FIT testing but were seen in a onestop flexible sigmoidoscopy clinic. Patients with rectal bleeding and no other symptoms and no anaemia were also seen in our one-stop clinic. Patients diagnosed with cancer in this onestop pathway could have CTC as part of their staging to exclude synchronous lesions if appropriate.

Local providers

Nottingham has two providers of urgent pathways for CRC. Historically, Nottingham University Hospitals NHS Trust saw $55.0 \%$ of two week wait (2WW) referrals and introduced Straight to test (STT) colonoscopy in August 2014 with prospective monitoring ${ }^{14}$. An independent provider (Circle Health, London, UK)) received $45.0 \%$ of referrals of $2 \mathrm{WW}$ referrals at a neighbouring Treatment Centre (TC). In each of these pathways, approximately $55.0 \%$ of referrals did not mention rectal bleeding as a reason for referral. The TC did not adopt STT when introduced ${ }^{14}$, did not participate in the "Getting FIT" pilot ${ }^{9}$ and did not adopt the RCCD as described above. Additionally, FIT was not used in our local Upper Gastrointestinal Cancer 2WW pathways nor in 2WW upgrades from routine or emergency clinical settings during the evaluation period.

Cohort and Data Collection

All patients that were subject of a FIT request between $7^{\text {th }}$ November 2017 and 31 st December 2018 were logged prospectively in our BCSP hub in order to ensure clinical governance of this novel pathway.

All patients referred to the Nottingham Colorectal Service STT team on an RCCD form between these dates were logged prospectively in our NUhCLEUS database that supports our STT pathway. Cancer Outcomes \& Services Datasets (COSD) were used to evaluate 
diagnoses of CRC recorded using ICD codes C18-C20 (excluding C18.1 Appendix) with a censor date of $31^{\text {st }}$ December 2018. NUH Trust data, electronic patient records and NUhCLEUS data were used for cross-checking and diagnosis data validation, as well as evaluation of diagnostics. Primary Care referral data was retrieved from Clinical Commissioning Groups (CCG's) datasets.

Data from our "Getting FIT" pilot", historical COSD and NUhCLEUS data were also used for comparison.

Statistical analysis

Data were assessed for normality using histograms and a Shapiro-Wilk test. Comparisons were made between continuous variables using the students t-test if normally distributed or Mann-Whitney if not normally distributed. Categorical data was summarised using frequencies and percentages. Comparisons were made between categorical data using Chi Squared tests. All statistics were performed using GraphPad Prism, GraphPad Software, San Diego, CA, USA. Tests of significance were considered significant if a P-value of less than 0.05 was obtained.

Funding

The pathway was commissioned locally to allow direct access to FIT for local GPs and all four local CCGs (Nottingham City, Nottingham North and East, Nottingham West and Rushcliffe) approved and jointly funded this pathway. The cost of each FIT test was agreed as $£ 17.50$ per sample to CCGs - this included postage, analysis and administration costs. The cost of a "window" referral was $£ 85$ and the cost of a referral with all mandatory results available was $£ 66$ - to reflect the additional administrative work required to maintain the "window". 


\section{Results}

FIT requests and results

6747 FIT test requests were made during the evaluation period (Figure 1a). 272 (4.0\%) requests were rejected as clinic details mentioned rectal bleeding as a symptom. $92(1.4 \%)$ duplicate requests were also received. 6383 kits were dispatched and 615 kits were not returned within 14 days $(9.6 \%)$ and 35 kits were spoiled on return or not suitable for analysis $(0.5 \%)$

5733 FIT results were available of which $4082(71.2 \%)$ were $<4 \mu \mathrm{g} \mathrm{Hb} / \mathrm{g}$ faeces, $579(10.1 \%)$ were 4-9.9 $\mu \mathrm{g} \mathrm{Hb} / \mathrm{g}$ faeces, 836 (14.6\%) were 10.0-149.9 $\mu \mathrm{g} \mathrm{Hb} / \mathrm{g}$ faeces, and $236(4.1 \%)$ were $\geq 150.0 \mu \mathrm{g} \mathrm{Hb} / \mathrm{g}$ faeces. The proportion of "rule out" results $<4.0 \mu \mathrm{g} \mathrm{Hb} / \mathrm{g}$ faeces was significantly higher than in the two week wait population tested during our pilot ${ }^{9}(71.2 \%$ vs $60.4 \%$, Chi squared $42.8, \mathrm{p}<0.0001$ ) and the proportion of "rule in" results $\geq 150.0 \mu \mathrm{g} \mathrm{Hb} / \mathrm{g}$ faeces was significantly lower ( $4.1 \%$ vs $8.1 \%$, Chi squared $27.3, \mathrm{P}<0.0001$ ) than in our pilot (Figure 1b).

The number of FIT requests showed a steady rise throughout the evaluation period but with signs of more selective usage towards the end of the evaluation period (Figure 2a). The demographics of patients who underwent FIT testing are shown in Table 1.

Two week wait referrals

Introduction of direct access to FIT and the Rapid Colorectal Cancer Diagnosis pathway was preceded by a dip in $2 \mathrm{WW}$ referrals to our Trust with an increase at the neighbouring TC (Figure $2 b$ and c). However, this then reverted in early 2018 with a steady rise in referrals to the Trust pathway thereafter, but no significant change in referrals to the TC pathway where 
FIT was not implemented, yielding approximately 33\% rise in referrals across Nottingham overall during the evaluation period.

Diagnostic capacity and first test

The numbers of monthly colonoscopy, flexible sigmoidoscopy and CT colon requests generated by the Trust $2 \mathrm{WW}$ pathway only are shown in Figure 3. There was a significant reduction in $2 \mathrm{WW}$ colonoscopy usage in the year after the introduction of FIT despite the rise in referrals when compared to the year prior to introduction ( $\mathrm{p}=0.016$, paired t test).

Colonoscopy usage rose through the year and approached levels similar to the previous year towards the end the first year. We observed a corresponding significant increase in CTC activity as first test $(\mathrm{p}<0.01$, Paired $\mathrm{t}$ test). A significant increase in flexible sigmoidoscopy usage $(\mathrm{p}<0.01$, Paired t test) was also evident but this change was not related to the use of FIT.

Colorectal Cancer (CRC) diagnoses

113 colorectal adenocarcinoma diagnoses were evident in patients who had been subject to a FIT request at the time of analysis. 4 (3.6\%) patients did not receive a kit as rectal bleeding was a recorded symptom and $3(2.7 \%)$ did not return their kit. 106 CRC diagnoses followed a FIT return, with 2 CRC diagnoses in 4082 patients with FIT results $<4.0 \mu \mathrm{g} \mathrm{Hb} / \mathrm{g}$ faeces between November 2017 and $31^{\text {st }}$ December 2018; one of which was a radiological diagnosis with no histological confirmation. 104 CRC diagnoses were recorded in 1285 patients with a positive FIT according to RCCD protocols - representing an overall detection rate of $8.1 \%$ (Table 2).

101 new CRC diagnoses were made in this cohort and 3 diagnoses of recurrent luminal disease after previous treatment were also made. In the new diagnosis group, 27 (26.7 \%) 
were Stage I tumours and 32 (31.7\%) were Stage II tumours (Table 2). Nearly half (12 of 26) Stage I CRC had a FIT result between 4.0 and $150.0 \mu \mathrm{g} \mathrm{Hb} / \mathrm{g}$ faeces.

The overall number of CRC diagnoses made across both Nottingham pathways has risen compared to the previous year despite the use of FIT for "rule out" and "first test selection" in our Trust pathway (Figure 5). The number of cancers diagnosed on 2WW pathways in Nottingham has shifted significantly towards the Trust where FIT was used in this way (Figure 5). In diagnoses made at our Trust, the ratio or CRCs diagnosed after 2WW GP referral compared to CRC's diagnosed after Routine GP referral shows a significant rise during the evaluation period.

\section{Discussion}

These data suggest a stage migration to early disease detection, with consequent improvement in clinical outcomes, may be achievable if FIT is used in all symptomatic patients. We have shown an increase in overall CRC detection rates and a significant shift towards $2 \mathrm{WW}$ diagnosis by introducing FIT in just one part of Nottingham's $2 \mathrm{WW}$ services for symptomatic patients. We demonstrate that a symptomatic pathway incorporating FIT may be more clinically effective than one based on an arbitrary distinction between "high risk" and "low risk" groups as currently defined ${ }^{3}$. Our data also show that introduction of FIT in Primary Care broadens the population selected for assessment by GPs. This is demonstrated by the fact that the rate of negative FIT results $(<4.0 \mu \mathrm{g} \mathrm{Hb} / \mathrm{g}$ faeces) is higher and the proportion of FIT results $\geq 150.0 \mu \mathrm{g} \mathrm{Hb} / \mathrm{g}$ faeces is lower than that described in our $2 \mathrm{WW}$ pathway pilot ${ }^{9}$. This was expected and represents inclusion of a lower risk population, in keeping with the intentions of NG12 when testing for occult blood in faeces was described ${ }^{3}$. This "opportunistic screening" probably underlies the trend towards earlier stage 
cancer that we observe in the cancers diagnosed on our Trust pathway and this is clearly the most promising aspect of FIT usage. The detection rate of $8.1 \%$ after a "positive" FIT at any level in patients without rectal bleeding is higher than we have demonstrated in previous evaluations ${ }^{7,13-14}$ suggesting improved clinical effectiveness overall. Current analysis suggests that introduction of FIT with a "rule out" contingency does not have a negative impact on diagnosis numbers. We acknowledge that further diagnoses of CRC after a FIT $<4.0 \mu \mathrm{g} \mathrm{Hb} / \mathrm{g}$ faeces may yet come to light with longer follow-up.

The reduction in demand on diagnostics after "rule out" is offset by increased use of FIT in the wider population prompting referrals in patients that may previously have been reassured. Thus, FIT has not reduced our 2WW pathway workload but simply changed the population we investigate. Therefore, it seems unlikely that FIT usage in symptomatic patients will create extra capacity in endoscopy unless higher thresholds are adopted, with consequent loss of sensitivity in symptomatic patients. Alternatively, the use of FIT to identify lower risk patients that may be more suitable for CTC, as well as use in older frailer patients, might allow 2WW colonoscopy usage to fall despite increased referrals overall. We have not reported here on Routine investigation after FIT testing which would of course add further demand for diagnostic capacity. We have described $15.0 \%$ routine investigation rate after negative FIT elsewhere ${ }^{13}$, but it is important to note that this figure might have been higher if 2WW referral had not been available at the TC (and for IDA via our UGI pathway). If introduction of FIT alone, at these very low thresholds for positivity, cannot create the colonoscopy capacity needed to allow lower thresholds in BCSP, scoring systems such as FAST $^{15}$ with additional modifications for $\mathrm{Hb}$, ferritin/iron and platelet levels, may allow improved positive predictive value for cancer in results between 4.0 and $150.0 \mathrm{~g} \mathrm{Hb} / \mathrm{g}$ faeces $^{5-9}$. Such an approach, combined with a switch to CTC for lower risk patients might curb the rise in endoscopy demand. 
The follow up of those patients who were reassured after a FIT $<4.0 \mu \mathrm{g} \mathrm{Hb} / \mathrm{g}$ faeces in this cohort remains short but consistent with other pathways using FIT in symptomatic patients ${ }^{16}$. The current data in Nottingham shows a low miss rate that may be unpalatable to the individual but is probably acceptable at a population level in a resource limited healthcare system. In the context, of increasing diagnoses on the most appropriate pathway and a shift towards early stage cancer diagnosis the overall benefit appears to outweigh the risk. In addition, if FIT is deemed a "reasonable" first test the impact on valid consent ${ }^{17}$ prior to colonoscopy is significant, especially in the unfortunate event of subsequent iatrogenic harm. Finally, increasing the number of cancers overall, the proportion diagnosed at early stage and the proportion diagnosed on $2 \mathrm{WW}$ pathways increases the number of patients that have to be treated within 62 days. This does have a negative impact on political targets for therapeutic services that are already full to bursting. Increased capacity for surgery and oncology may be required, alongside changes to diagnostic capacity as described above. In light of the limited benefit, if any, of treating CRC within 62 days of diagnosis ${ }^{18-19}$, a political shift that promotes introduction of FIT over 62 day performance for CRC, may be a timely incentive for care systems looking to improve their early diagnosis rates for this common cause of cancer death. 
References

1. Richards M, Thorlby R, Fisher R, Turton C. Unfinished Business: An assessment of the national approach to improving cancer services in England 1995-2015. The Health Foundation [Internet]. 2018. Available online: http://reader.health.org.uk/unfinishedbusiness [Accessed 9 April 2019].

2. Cancer Research UK. Bowel Cancer Statistics, 2018. Available online: http://www.cancerresearchuk.org/health-professional/cancer-statistics/statistics-bycancer-type/bowel-cancer [Accessed 5 January 2019].

3. National Institute for Health and Clinical Excellence. Suspected cancer: recognition and referral. NICE guidelines [NG12] 2015. Available online:

https://www.nice.org.uk/guidance/NG12/chapter/1-Recommendations-organised-bysite-of-cancer\#lower-gastrointestinal-tract-cancers [Accessed 5 January 2019].

4. Logan RFA, Patnick J, Nickerson C, Coleman L, Rutter MD, von Wagner C. English Bowel Cancer Screening Evaluation Committee. Outcomes of the Bowel Cancer Screening Programme (BCSP) in England after the first 1 million tests. Gut 2012;61(10):1439-1446.

5. Hamilton W, Lancashire R, Sharp D, Peters TJ, Cheng KK, Marshall T. The importance of anaemia in diagnosing colorectal cancer: a case-control study using electronic primary care records. Br J Cancer 2008;98(2):323-7.

6. Atkin W, Wooldrage K, Shah U, Skinner K, Brown JP, Hamilton W, et al. Is wholecolon investigation by colonoscopy, computerised tomography colonography or barium enema necessary for all patients with colorectal cancer symptoms, and for which patients would flexible sigmoidoscopy suffice? A retrospective cohort study. Health Technol Assess 2017;21(66):1-80. 
7. Mashlab S LP, Laing W, Ng O, D'Auria M, Thurston D, Thomson S, et al. Anaemia helps to stratify risk in symptomatic patients referred on a 2 week wait pathway for colorectal cancer. Ann R Coll Surg Engl 2018;100(5):350-56.

8. Bailey SE, Ukoumunne OC, Shephard EA, Hamilton W. Clinical relevance of thrombocytosis in primary care: a prospective cohort study of cancer incidence using English electronic medical records and cancer registry data. Br J Gen Pract 2017;67(659):e405-e13.

9. Chapman C, Bunce J, Oliver S, Ng O, Tangri A, Rogers R et al. “Getting FIT”: A service evaluation of FIT and anaemia for risk stratification in the Two week wait pathway for Colorectal Cancer. BJS Open 2019;3(3): 395-402.

10. Jellema P, van der Windt DA, Bruinvels DJ, Mallen CD, van Weyenberg SJ, Mulder $\mathrm{CJ}$, et al. Value of symptoms and additional diagnostic tests for colorectal cancer in primary care: systematic review and meta-analysis. BMJ 2010;340:c1269.

11. Mowat C, Digby J, Strachan JA, Wilson R, Carey FA, Fraser CG, et al. Faecal haemoglobin and faecal calprotectin as indicators of bowel disease in patients presenting to primary care with bowel symptoms. Gut 2016;65(9):1463-9.

12. Widlak MM, Thomas CL, Thomas MG, Tomkins C, Smith S, O'Connell N, et al. Diagnostic accuracy of faecal biomarkers in detecting colorectal cancer and adenoma in symptomatic patients. Aliment Pharmacol Ther 2017;45(2):354-63.

13. McKinney R, Chapman C, Morling J, Weller J, Tangri A, Simpson JA, et al. Keeping FIT: Early Clinical Outcomes of a novel two week wait pathway for colorectal cancer using faecal immunochemical testing. Colorectal Dis 2019;21(2):10.

14. Banerjea A, Voll J, Chowdhury A, Siddika A, Thomson S, Briggs R, et al. Straightto-test colonoscopy for two-week wait referrals improves time to diagnosis of 
colorectal cancer and is feasible in a high-volume unit. Colorectal Dis 2017;19(9):819-26.

15. Cubiella J, Digby J, Rodriguez-Alonso L, Vega P, Salve M, Diaz-Ondina M, et al. The fecal hemoglobin concentration, age and sex test score: Development and external validation of a simple prediction tool for colorectal cancer detection in symptomatic patients. Int J Cancer 2017;140(10):2201-11.

16. Juul JS, Hornung N, Andersen B, Laurberg S, Olesen F, Vedsted P. The value of using the faecal immunochemical test in general practice on patients presenting with non-alarm symptoms of colorectal cancer. Br J Cancer, 2018;119(4): 471-479.

17. Montgomery (Appellant) v Lanarkshire Health Board (Respondent) [2015] UKSC 11.

18. Thorne K, Hutchings HA, Elwyn G. The effects of the Two-Week Rule on NHS colorectal cancer diagnostic services: a systematic literature review. BMC health services research 2006;6:43.

19. Leung E, Grainger J, Bandla N, Wong L. The effectiveness of the '2-week wait' referral service for colorectal cancer. International journal of clinical practice 2010;64(12):1671-4. 
Table 1. Demographics of all patients undergoing FIT requests, all patients with a FIT result and patients stratified by FIT result.

\begin{tabular}{|c|c|c|c|c|c|c|c|c|}
\hline & All requests & All results & $\begin{array}{l}\mathrm{FIT} \geq 150.0 \mu \mathrm{g} \\
\mathrm{Hb} / \mathrm{g} \text { faeces }\end{array}$ & $\begin{array}{l}\text { FIT } 10.0- \\
149.9 \mu \mathrm{g} \mathrm{Hb} / \mathrm{g} \\
\text { faeces }\end{array}$ & $\begin{array}{l}\text { FIT } 4.0-9.9 \mu \mathrm{g} \\
\mathrm{Hb} / \mathrm{g} \text { faeces with } \\
\text { anaemia }\end{array}$ & $\begin{array}{l}\text { FIT 4.0-9.9ug } \\
\text { Hb/g faeces } \\
\text { without anaemia }\end{array}$ & $\begin{array}{l}\text { FIT }<4.0 \mu \mathrm{g} \\
\mathrm{Hb} / \mathrm{g} \text { faeces }\end{array}$ & \\
\hline Patients & 6747 & 5733 & 236 & 836 & 297 & 282 & 4082 & \\
\hline $\begin{array}{l}\mathrm{M}: \mathrm{F} \\
(\%)\end{array}$ & $\begin{array}{l}2990: 3757 \\
(44: 56)\end{array}$ & $\begin{array}{l}2522: 3210 \\
(44: 56)\end{array}$ & $\begin{array}{l}138: 98^{*} \\
(58: 42)\end{array}$ & $\begin{array}{l}377: 458 \\
(45: 55)\end{array}$ & $\begin{array}{l}131: 166 \\
(44: 56)\end{array}$ & $\begin{array}{l}107: 175 \\
(38: 62)\end{array}$ & $\begin{array}{l}1768: 2314 \\
(43: 57)\end{array}$ & $\begin{array}{l}* \text { Chi squared } \\
20.9(\mathrm{P}<0.0001)\end{array}$ \\
\hline $\begin{array}{l}\text { Mean Age }(y) \\
( \pm \text { Standard Error of the Mean })\end{array}$ & 66.7 & $\begin{array}{l}67.4 \\
(0.18)\end{array}$ & $\begin{array}{l}71.9 \\
(0.88)\end{array}$ & $\begin{array}{l}71.9 \\
(0.45)\end{array}$ & $\begin{array}{l}72.6 \\
(0.65)\end{array}$ & $\begin{array}{l}68.5 \\
(0.80)\end{array}$ & $\begin{array}{l}65.7 \\
(0.48)\end{array}$ & \\
\hline Proportion of all FIT results (\%) & & $100 \%$ & $4.0 \%$ & $14.6 \%$ & $5.2 \%$ & $4.9 \%$ & $71.2 \%$ & \\
\hline
\end{tabular}


Table 2 Colorectal cancer detection rates and Stage of cancers in patients with FIT results. *Patients tested towards the end of the evaluation period may not have completed investigations or diagnoses may not have been recorded in Cancer Outcomes and Services Dataset (COSD) by the censor date of 31/12/18 therefore these numbers shall rise in time. Not all patients were referred for investigation as per Rapid Colorectal Cancer Pathway protocols.

\begin{tabular}{|c|c|c|c|c|c|c|}
\hline & Total & $\begin{array}{l}\text { FIT } \geq 150.0 \mu \mathrm{g} \mathrm{Hb} / \mathrm{g} \\
\text { faeces }\end{array}$ & 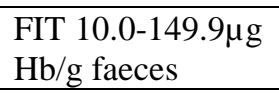 & 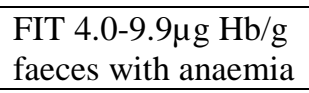 & $\begin{array}{l}\text { FIT } 4.0-9.9 \mu \mathrm{g} \mathrm{Hb} / \mathrm{g} \\
\text { faeces without anaemia }\end{array}$ & $\begin{array}{l}\text { FIT }<4.0 \mu \mathrm{g} \mathrm{Hb} / \mathrm{g} \\
\text { faeces }\end{array}$ \\
\hline Patients & 5733 & 236 & 836 & 213 & 366 & 4082 \\
\hline $\begin{array}{l}\text { Colorectal cancers detected post } \\
\text { FIT* } \\
(\%) \\
\text { Overall detection rate }(\%) \sim \\
\end{array}$ & $\begin{array}{l}106 \\
2.0\end{array}$ & $\begin{array}{l}63 \\
26.7\end{array}$ & $\begin{array}{l}38 \\
4.5\end{array}$ & $\begin{array}{l}2 \\
0.9\end{array}$ & $\begin{array}{l}1 \\
0.3\end{array}$ & $\begin{array}{l}2 \\
<0.1\end{array}$ \\
\hline $\begin{array}{l}\text { New CRC diagnoses: } \\
\text { Stage I }(\%) \\
\text { Stage II }(\%) \\
\text { Stage III }(\%) \\
\text { Stage IV }(\%)\end{array}$ & $\begin{array}{l}103 \\
27(26.2) \\
32(31.1) \\
23(22.3) \\
21(20.4)\end{array}$ & $\begin{array}{l}60 \\
14(13.6) \\
24(23.3) \\
12(11.6) \\
10(9.7)\end{array}$ & $\begin{array}{l}38 \\
12(11.6) \\
7(6.8) \\
9(8.7) \\
10(9.7)\end{array}$ & $\begin{array}{l}2 \\
0 \\
0 \\
1(1.0) \\
1(1.0)\end{array}$ & $\begin{array}{l}1 \\
0 \\
0 \\
1(1.0) \\
0\end{array}$ & $\begin{array}{l}2 \\
1(1.0) \\
1(1.0) \\
0 \\
0\end{array}$ \\
\hline Luminal recurrences & 3 & 3 & 0 & 0 & 0 & 0 \\
\hline
\end{tabular}


Figure 1 a) Flow diagram of patients with FIT requests from referral to Colorectal Cancer (CRC) diagnosis. ( $\mathrm{Hb}-$ Haemoglobin)

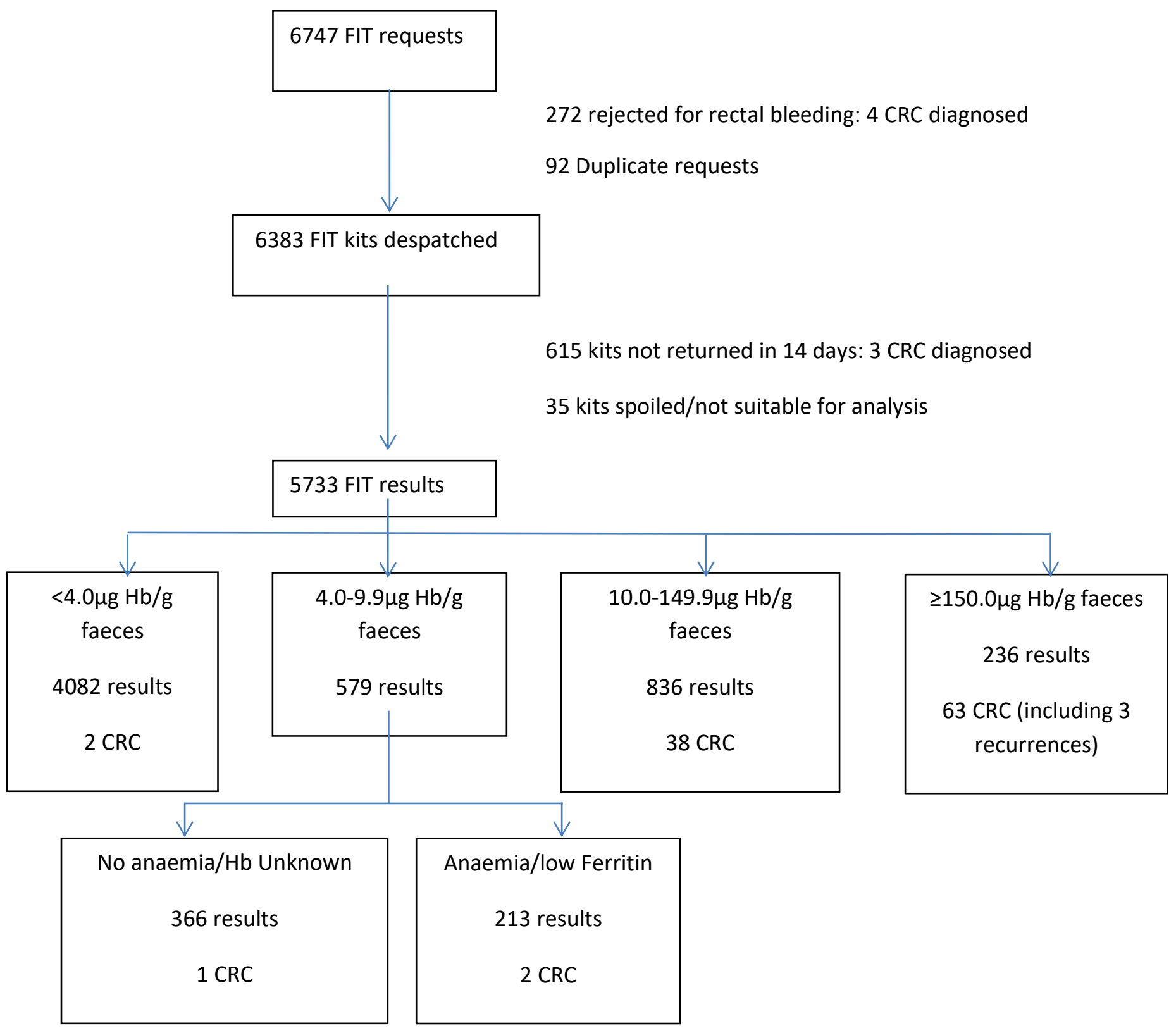


Figure 1b) Comparison of FIT result breakdown during "Keeping FIT" (November 2017 - December 2018) and "Getting FIT" pilot (September 2016- August 2017) ${ }^{9}$ by results strata: $<4.0 \mu \mathrm{g} \mathrm{Hb} / \mathrm{g}$ faeces,

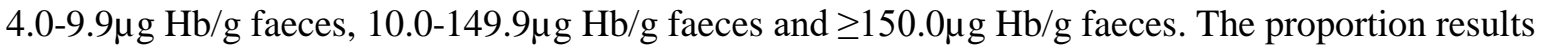
$<4.0 \mu \mathrm{g} \mathrm{Hb} / \mathrm{g}$ faeces was significantly higher $(71.2 \%$ vs $60.4 \%$, Chi squared $42.8, \mathrm{p}<0.0001)$ and the proportion of "rule in" results $\geq 150.0 \mu \mathrm{g} \mathrm{Hb} / \mathrm{g}$ faeces was significantly lower ( $4.1 \%$ vs $8.1 \%$, Chi squared 27.3,P<0.0001) during "Keeping FIT".

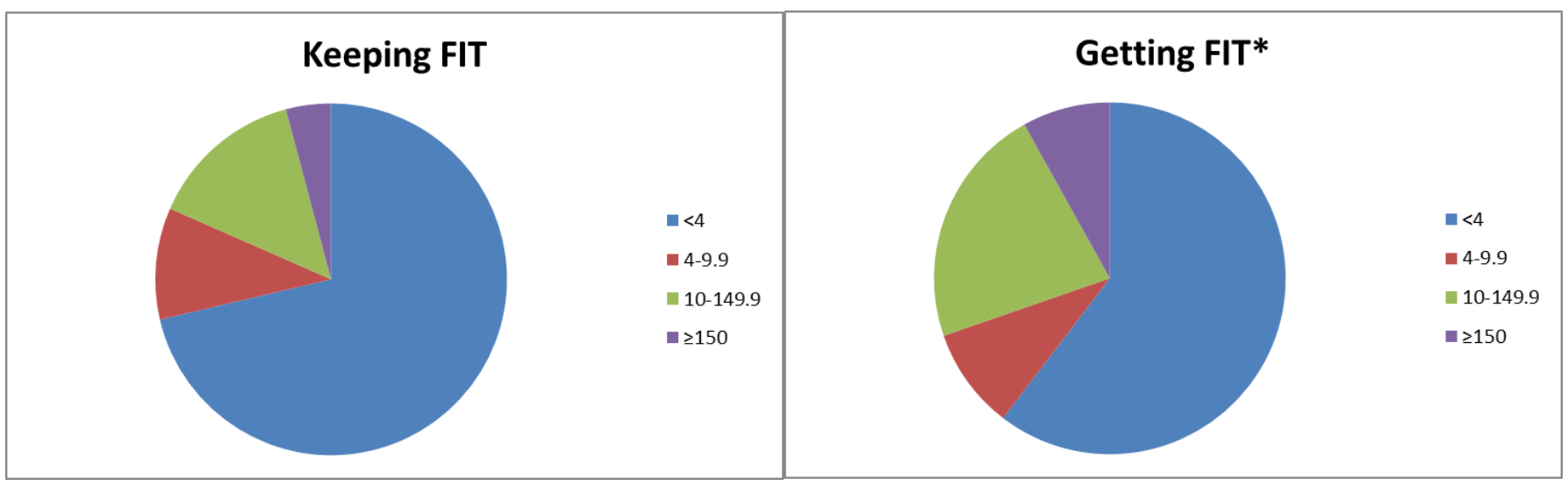


Figure 2a) Rising trend of FIT requests received during the evaluation period.

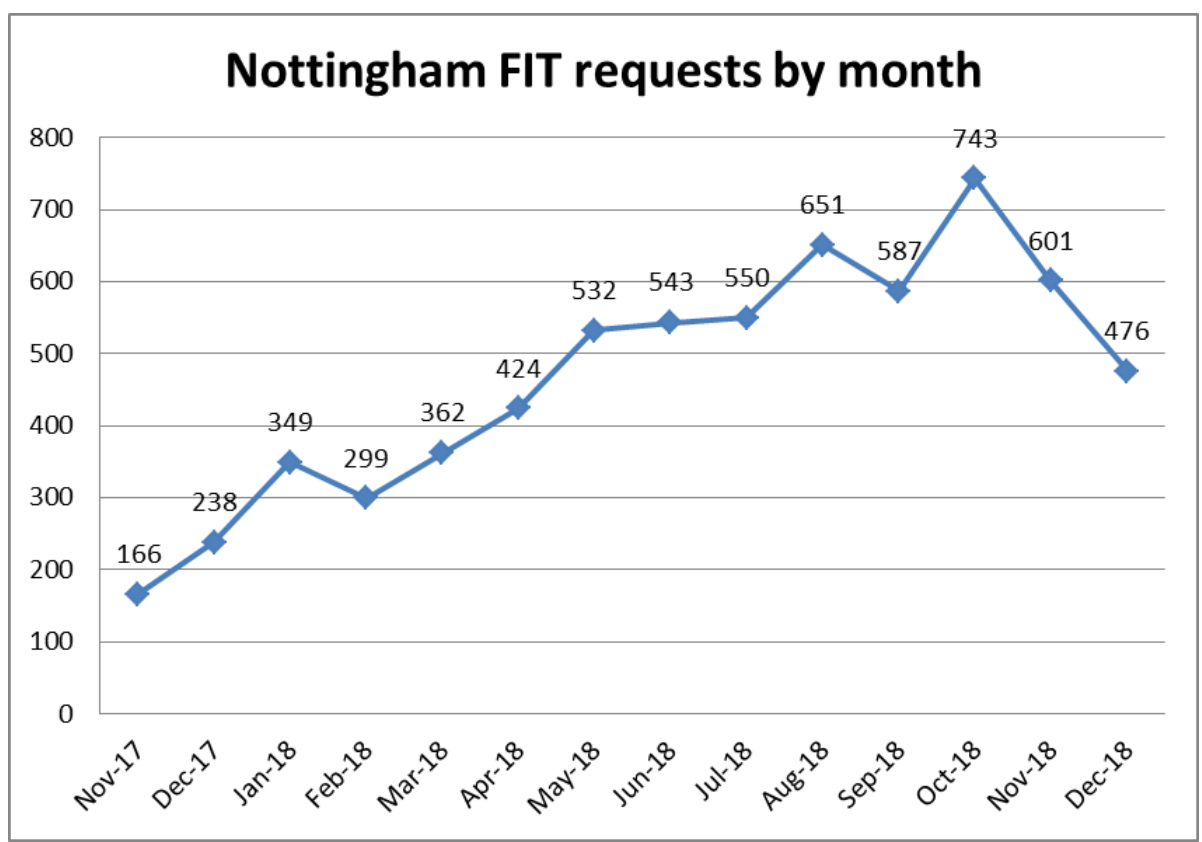

Figure 2b) Number of two week wait referrals received across both pathways in Nottingham from April 2016 to October 2018. Red arrow marks introduction of Rapid Colorectal Cancer Diagnosis Pathway.

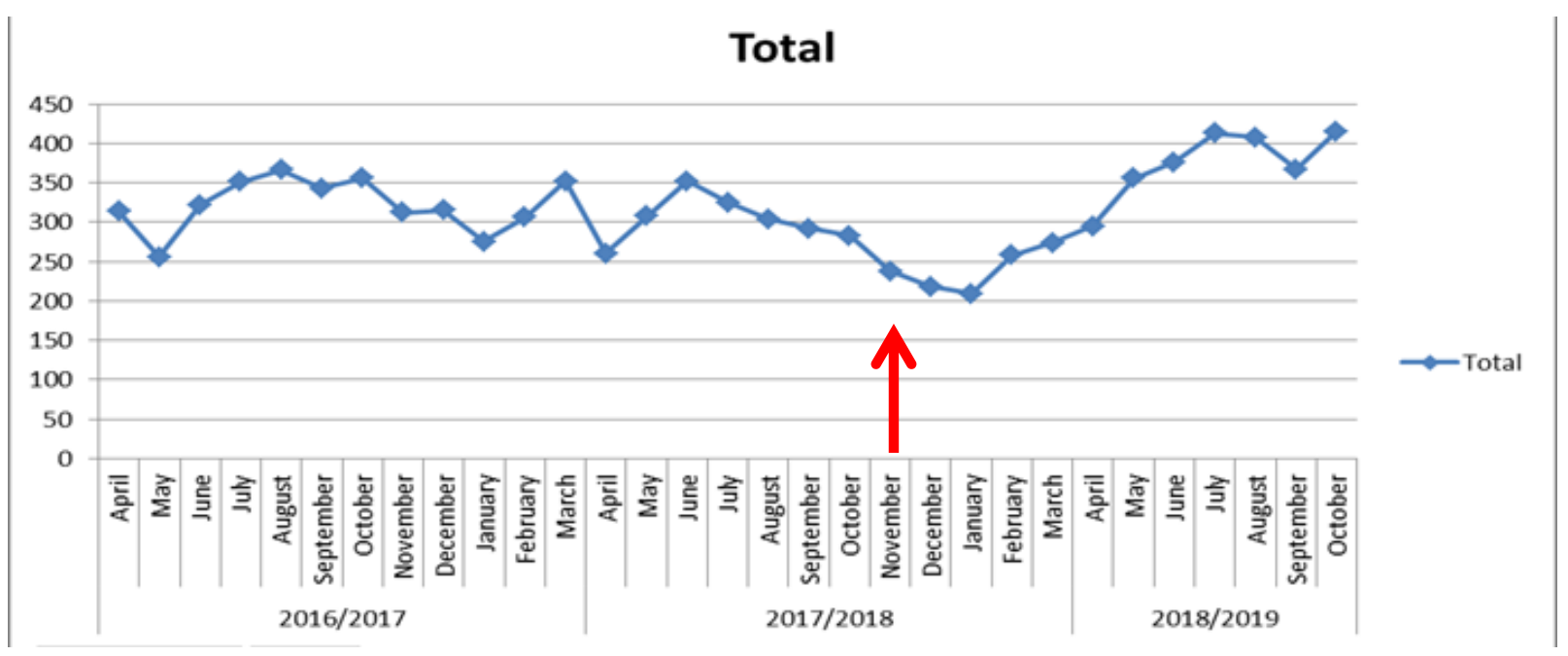


Figure 2c) Two week wait referrals from April 2016 to October 2018 by provider: Nottingham University Hospitals NHS Trust using FIT (and Straight to test) as described and Nottingham Treatment Centre (Circle) not using FIT. Red arrow marks introduction of Rapid Colorectal Cancer Diagnosis Pathway.

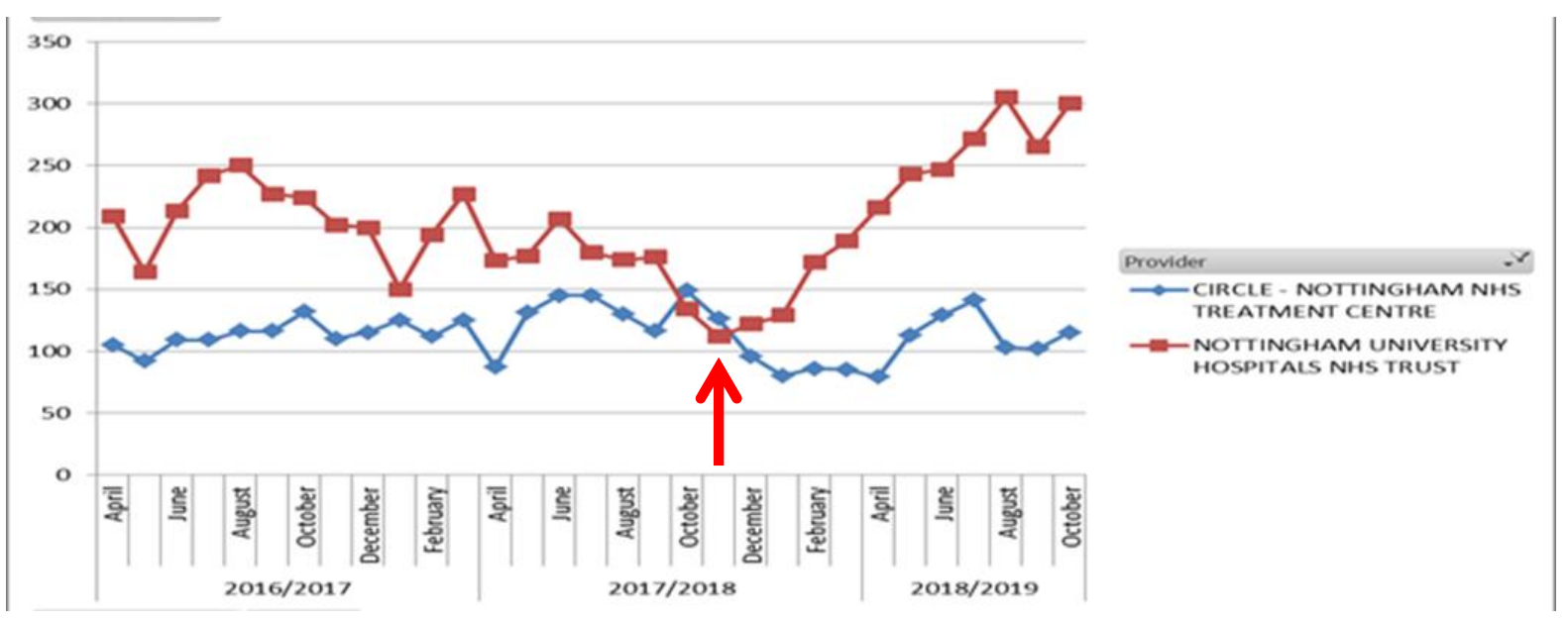


Figure 3 Two week wait (2WW) colonoscopy, flexible sigmoidoscopy and CT colonography requests generated after a Rapid Colorectal Cancer Diagnosis pathway referral to Nottingham University Hospitals NHS Trust or FIT result $\geq 150.0 \mu \mathrm{g} \mathrm{Hb} / \mathrm{g}$ faeces only. Activity for November 2017 October 2018 "Keeping FIT" is compared with the preceding year (November 2016 - October 2017) prior to pathway introduction. $2 \mathrm{WW}$ requests from other sources and requests at Nottingham Treatment Centre are not shown as FIT was not used in these pathways.

3a) Significant reduction in colonoscopy requests in 2017-18 compared to previous year ( $\mathrm{p}=0.016$, paired $t$ test).

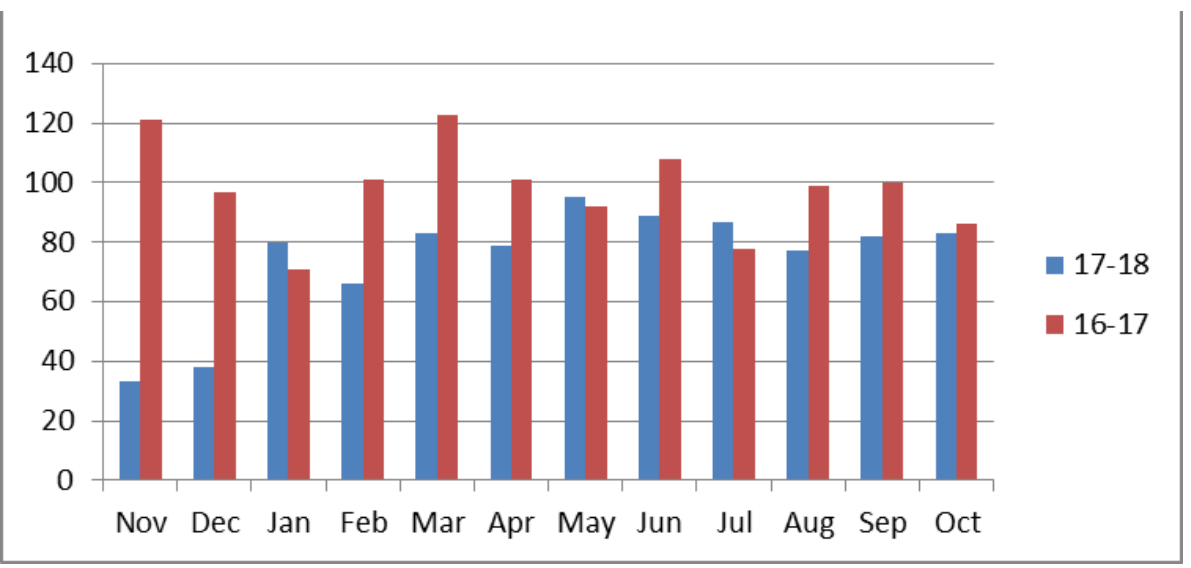

3b) Significant increase in flexible sigmoidoscopy requests in 2017-18 compared to previous year $(\mathrm{p}<0.01$, paired $\mathrm{t}$ test $)$.

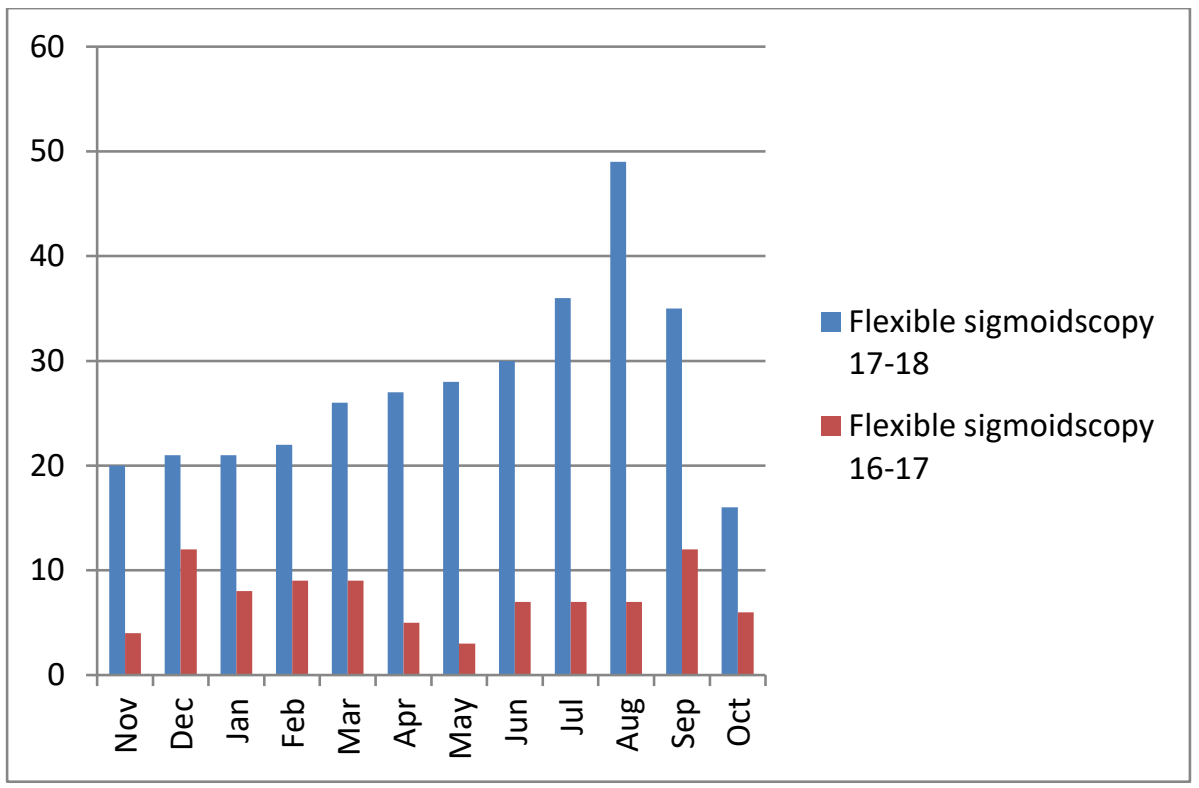


3c) Significant increase in CTC requests in 2017-18 compared to previous year ( $\mathrm{p}<0.01$, paired $\mathrm{t}$ test).

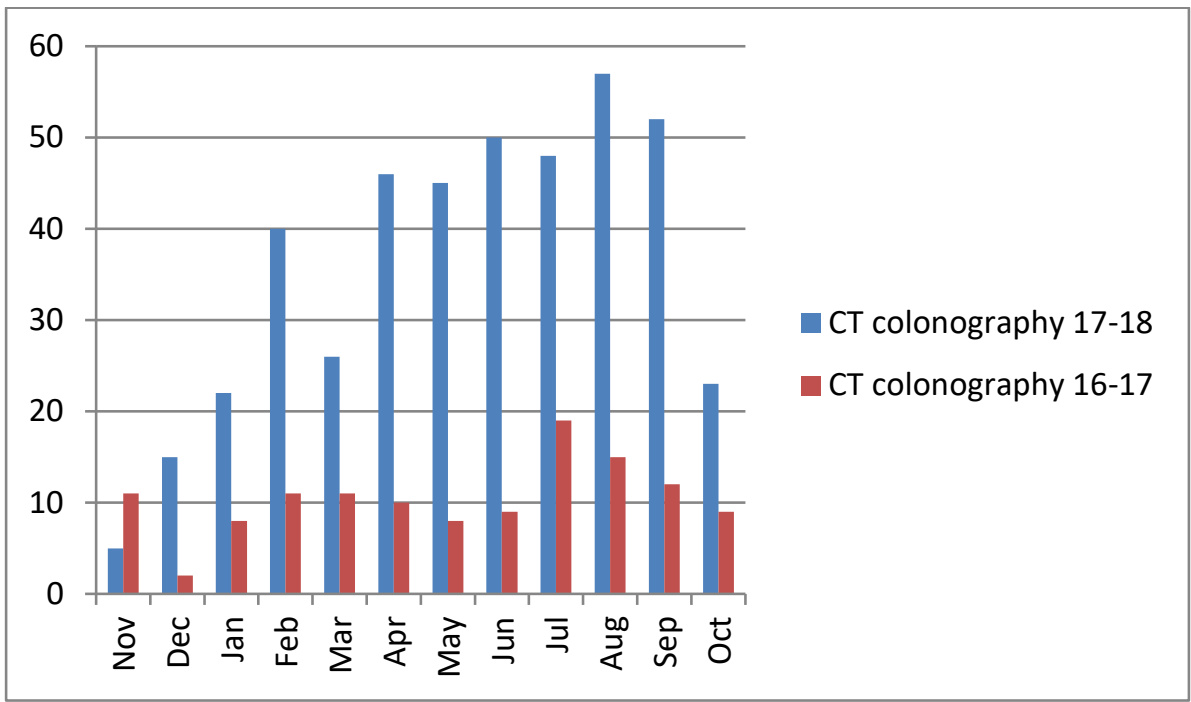


Figure 4a The number of colorectal cancers diagnosed in Nottingham continues to rise despite the "rule out" mechanism adopted in symptomatic patients, with a rise in diagnoses associated with GP referral as well as other routes.

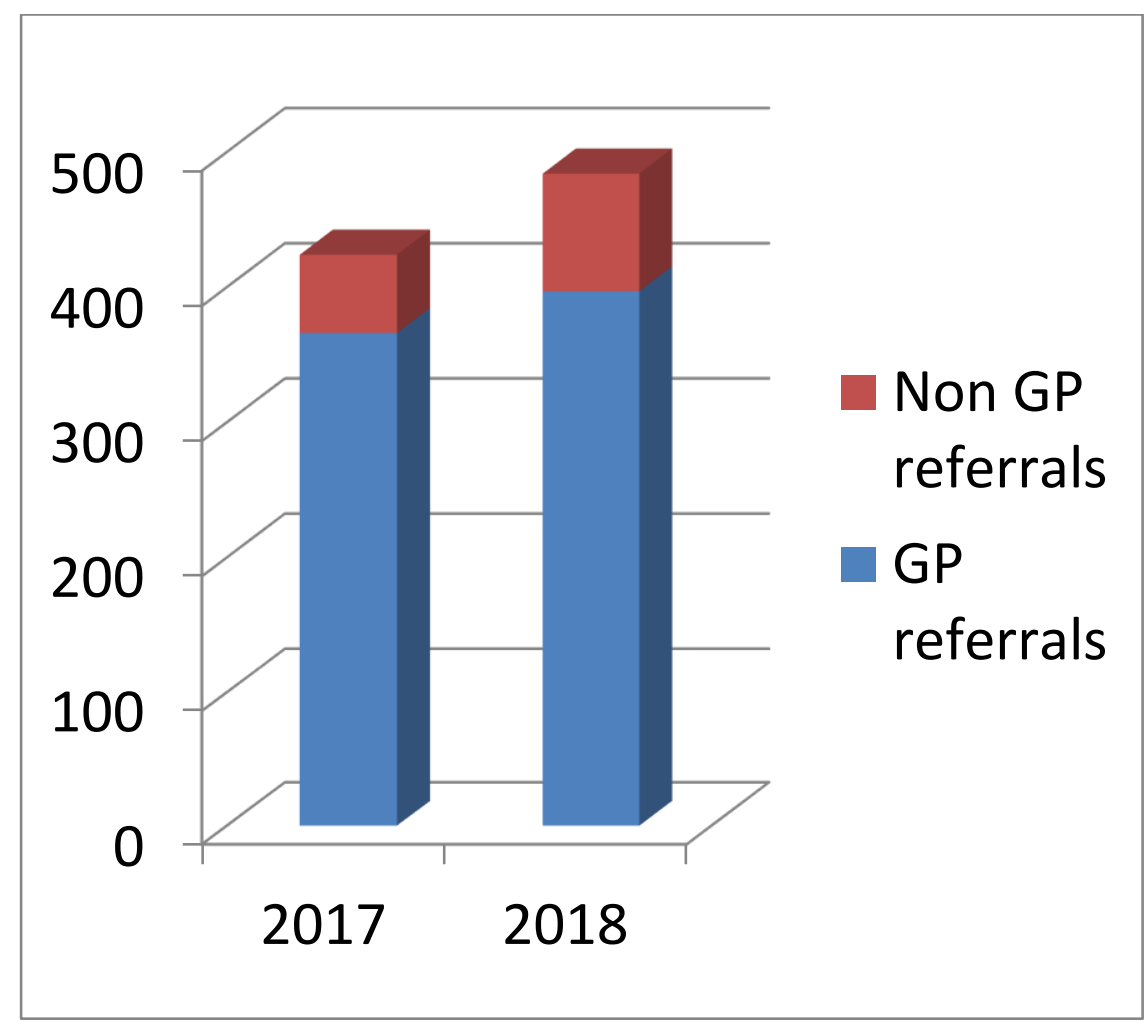

Figure 4b Significant rise in the proportion of all Nottingham CRC diagnoses made after a Two week wait referral to Nottingham University Hospitals NHS Trust (NUH) compared to Nottingham Treatment Centre (TC) in 2017-18 versus 2016-17 (68.2\% vs 57.5\%, Chi squared $=5.2, \mathrm{p}=0.02)$.

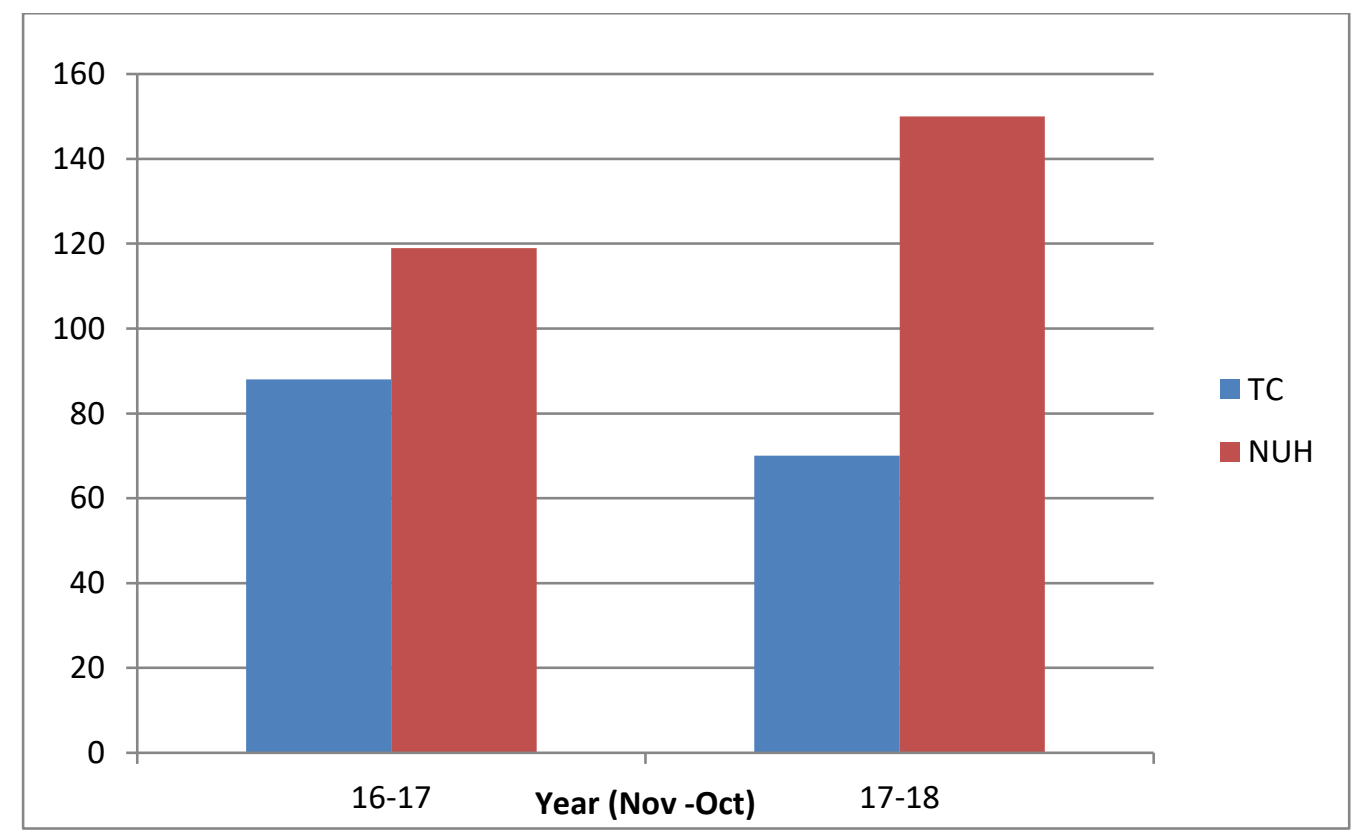


Figure 5 Ratio of CRC diagnoses made at Nottingham University Hospitals NHS Trust after an urgent referral to those made after a routine referral from November 2016 to October 2018). Ratio below 1 indicates more diagnoses made on routine pathways and Ratio above 1 indicates more diagnoses made on urgent (two week wait) pathways.

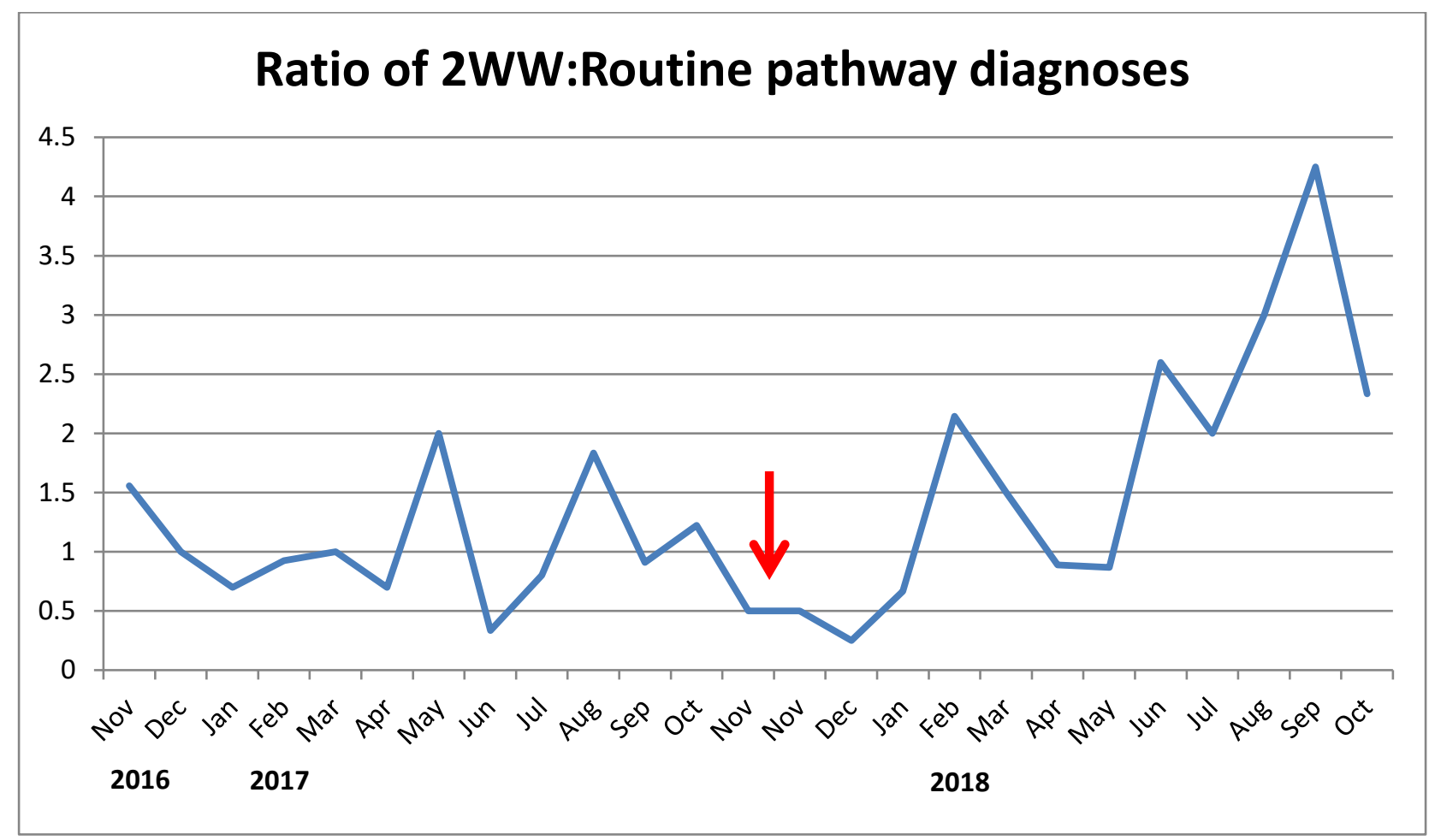




\section{$\underline{\text { Appendix }}$}

FIT testing process - additional detail for FITTER checklist:

All patients referred without rectal bleeding were sent (by normal UK Post Office mail system) a faecal sample collection device (OC-Sensor ${ }^{\mathrm{TM}}$, Eiken Chemical Co, Tokyo, Japan) within 2 days of the $2 \mathrm{WW}$ referral being received. The haemoglobin concentration in the OC-Sensor FIT is determined in nanograms of haemoglobin per millilitre of buffer in the sample tube $(\mathrm{ng} / \mathrm{ml})$. Each sample tube contains $2 \mathrm{ml}$ of stabilising sample buffer in which, with the aid of the test-wand, $10 \mathrm{mg}$ of stool sample is suspended. Final results are reported in $\mu \mathrm{g} \mathrm{Hb} / \mathrm{g}$ faeces.

The device was pre-labelled with the patient's name, NHS number, a unique laboratory ID number and a space to add the sample date. An instruction leaflet for using the sampling device, a letter outlining the purpose of the test and clarifying that the results would not be used for diagnostic purposes in isolation, and a prepaid first class return envelope were also included. Participants were asked to sample their faeces according to instructions, date the sampling device, and return it to the laboratory as soon as possible within 14 days of receipt of the letter. The process for kit dispatch and return was entirely postal.

All returned samples were logged prospectively at the receiving laboratory and analysed once for f$\mathrm{Hb}$ using the automated OC-Sensor ${ }^{\mathrm{TM}}-\mathrm{iO}$ (Eiken Chemical Co., Tokyo, Japan) according to manufacturer's protocols, alongside $\mathrm{f}-\mathrm{Hb}$ controls. The analyser was calibrated once a month, and 2 levels of controls were validated at the beginning and end of each run. Returned samples were stored in a refrigerator at $4{ }^{\circ} \mathrm{C}$ upon arrival until analysis. All samples were analysed within 1 week of receipt.

If sample values were above the linearity of the assay $(200 \mu \mathrm{g} \mathrm{Hb} / \mathrm{g}$ faeces) they were diluted in OC Calibration Diluent (1 in 10 and 1 in 100) in order to obtain a quantitative result.

The manufacturer's quoted limit of quantitation for the $\mathrm{OC}$-sensor $\mathrm{iO}$ is $4.0 \mu \mathrm{g} \mathrm{Hb} / \mathrm{g}$ faeces with limit for detection as $2.0 \mu \mathrm{g} \mathrm{Hb} / \mathrm{g}$ faeces. The LOQ was also confirmed locally following analysis of a) 
spiked diluted patient samples, $\mathrm{n}=50$ (sample average of $4.4 \mu \mathrm{g} \mathrm{Hb} / \mathrm{g}$ faeces, $\mathrm{CV}=10.5 \%$ ); and $\mathrm{b}$ ) repeated measurements ( $n=6-11)$ of 5 independent patient samples (47 measurements) who had a mean $\mathrm{f}-\mathrm{Hb}$ level of between 4.0 and $5.0 \mu \mathrm{g} \mathrm{Hb} / \mathrm{g}$ faeces and mean $\mathrm{CV}$ of $9.0 \%$

Analyses were carried out in our laboratories located at the Eastern Bowel Cancer Screening Hub, Nottingham, England. These laboratories are UKAS (The United Kingdom Accreditation Service) accredited (ISO 15189) and take part in the UK NEQAS (The United Kingdom National External Quality Assessment Service) external quality assessment schemes.

All results were automatically uploaded to an electronic reporting system that communicated with both primary and secondary care electronic results systems. In addition, high readings FIT $\geq 150.0 \mu \mathrm{g}$ $\mathrm{Hb} / \mathrm{g}$ faeces were notified by email to the Nottingham Colorectal Service STT team weekly, for direct contact as agreed in the new pathway. Laboratory staff was not involved in any clinical assessment or investigations and were therefore blinded to outcomes. 